\title{
Factors associated with staff and physician influenza immunization at a children's hospital in Ontario, Canada
}

This article was published in the following Dove Press journal:

International Journal of General Medicine

22 August 2012

Number of times this article has been viewed

\section{Raywat Deonandan \\ Ghada Al-Sulaiti \\ Asha Gajaria \\ Kathryn N Suh}

School of Interdisciplinary Health Sciences, Faculty of Health Sciences, University of Ottawa, Ottawa,

Ontario, Canada
Correspondence: Raywat Deonandan School of Interdisciplinary Health Sciences, Faculty of Health Sciences, University of Ottawa, 35 University Pvt, Ottawa, Canada KIN 6N5

Email raywat.deonandan@uottawa.ca
Abstract: In 2005, employees and physicians of the Children's Hospital of Eastern Ontario were surveyed about their experiences with and receipt of the 2003-2004 influenza vaccination. With a $29 \%$ response rate, $91 \%$ of respondents stated that they had received the 2003-2004 vaccine, and physicians were the most likely to have done so (97.2\%). Using logistic regression, the only factor significantly predictive of whether an employee or physician received the vaccine was whether they had awareness of a previous formal influenza immunization campaign.

Keywords: influenza vaccination, staff, pediatric hospital

\section{Introduction}

Infection with seasonal influenza can cause serious morbidity and mortality in hospitalized patients. ${ }^{1}$ The reported effectiveness of the modern trivalent influenza vaccine ranges from $74 \%{ }^{2}$ to $89.4 \%,{ }^{3}$ depending upon the population and study type. Immunization of health care workers is a proven strategy for reducing the mortality of vulnerable populations in an institutional setting. ${ }^{4,5}$ While influenza can be transmitted to patients by infected health care providers, uptake of the vaccine by health care workers is not at an expected or acceptable level. Asymptomatic infection is common, reported to occur in up to $23 \%$ of health care workers. ${ }^{6}$ In addition, health care workers continue to report for work despite the presence of influenza symptoms. ${ }^{7}$ A recent review of Australian studies showed the rate of Australian health care worker immunization to be $16.3 \%-58.7 \%,{ }^{8}$ with higher rates reported in hospitals with active vaccination campaign programs.

Beyond the obvious and immediate benefits to the vulnerable patient population are the measurable economic benefits that immunization provides. Health care workers who are vaccinated against influenza are less likely to acquire infection, and even if they become infected, the symptoms are likely to be less severe. Therefore, vaccination results in reduced staff absenteeism and illness. ${ }^{9}$

Given that uptake of the influenza vaccine by health care workers in most hospital settings is less than optimal, it is important to understand the factors that are associated with a failure to, or unwillingness to, become immunized. A programmatic response can then target these determinants more effectively. ${ }^{10}$

At the Children's Hospital of Eastern Ontario (CHEO) in Ottawa, Ontario, an influenza immunization campaign for employees and physicians is conducted by Occupational Health and Safety every year. The availability of the vaccine is advertised through several media, including a reminder included in employees' pay stubs. 
Prior to this survey, seasonal influenza immunization rates among CHEO staff and physicians were 63\% in 2001-2002 and 69\% in 2002-2003. In 2003-2004, the season of interest for this survey, the immunization rate was $77 \%$. This study describes the knowledge, attitudes, and behaviors associated with receipt of the influenza vaccination during the 2003-2004 influenza season.

\section{Materials and methods}

The CHEO is a 150-bed tertiary-care, academic pediatric acute care facility serving eastern Ontario and western Quebec. During the study period, 1906 staff and 150 physicians worked at $\mathrm{CHEO}$ as their primary place of employment. A 10-minute, self-administered, bilingual (English and French) survey was developed and piloted among small groups of employees and physicians for comprehensibility and flow. The survey was delivered to all CHEO staff with pay stubs, and to physicians electronically by email, in October 2005. The survey consisted of 28 questions, the most pertinent of which were, "Did you get the influenza vaccine last fall or winter (2003-2004)?", "Do you think the influenza vaccine is effective in preventing influenza?", and "Do you think the influenza vaccine can give you the influenza?" Reminders were sent out 2 and 4 weeks after the first mailing.

All employees of the hospital were invited to participate in the study. Health care providers who were not physicians or nurses (ie, physiotherapists, occupational therapists, and rehabilitation therapists) were combined into the category of "other health care providers". Employees in nonclinical roles (eg, personal support workers, administrative staff, food services employees, researchers, and students) were combined into the category called "nonhealth care workers".

Data from completed surveys were entered into an electronic database. Duplicate entries were identified by scanning for repeated unique identifiers (name or identification badge number). Unique identifiers were subsequently deleted to retain respondent anonymity. Accuracy of data entry was validated by duplicate entry of $10 \%$ of completed surveys.

Basic frequencies, cross-tabulations, and $t$-tests were computed using SPSS version 12.0 (SPSS Inc, Chicago, IL), with $P$ values for Fisher's Exact test computed using the open source computing package " $\mathrm{R}$ ". A logistic regression analysis was performed using a backwards elimination method to model covariates associated with self-reported immunization status in 2003-2004. An interaction term was included to control for the relationship between respondent age and length of employment with the hospital. This study was approved by the CHEO research ethics board.

\section{Results}

In total, 588 surveys were returned from 2056 staff and physicians (response rate 29\%), $84.5 \%$ of whom were female. Respondents had a mean age of 31.0 years and an average length of employment at CHEO of 12.6 years. The 10 occupation categories originally asked for in the survey were collapsed into four, due to cell sample size constraints (Table 1).

Ninety-one percent of respondents stated that they had received the influenza vaccine in 2003-2004, and six respondents did not answer the question. Only 6.5\% reported that they believed the vaccine could actually cause influenza. Table 2 summarizes the responses to the primary questions across the categories of respondents' occupations. Physicians, although small in number, were the most likely to have been vaccinated $(97.2 \%)$, and were also most likely to have been vaccinated prior to the current season $(94.3 \%)$.

Those who were nonimmunized were more likely to think the vaccine causes influenza $(14.6 \%$ versus $6.5 \%, P<0.05)$, less likely to think the vaccine was effective $(44.9 \%$ versus $68.5 \%, P<0.001)$ and more likely to think that fever is a possible side effect $(93.3 \%$ versus $75.8 \%, P=0.012)$. Those who were immunized were more likely to consider the influenza vaccine to be a "professional obligation" (78.4\% versus $34.7 \%, P<0.001)$. There was no statistically significant difference between those who were immunized and those who were not with respect to expecting side effects of paralysis, pain, or rash.

Table 3 presents a summary of the reasons that nonimmunized respondents provided for not receiving the

Table I Distribution of original and recoded professional categories

\begin{tabular}{|c|c|c|c|}
\hline $\begin{array}{l}\text { Collapsed and } \\
\text { recoded categories }\end{array}$ & $\begin{array}{l}\text { Original professional } \\
\text { categories }\end{array}$ & $\mathbf{n}$ & $\%$ \\
\hline Physician & Staff physician & 37 & 6.3 \\
\hline Nurse & Nurse & 230 & 39.1 \\
\hline $\begin{array}{l}\text { Other health care } \\
\text { provider }\end{array}$ & $\begin{array}{l}\text { Other health care provider } \\
\text { (physiotherapist, occupational } \\
\text { therapist, respiratory technician) }\end{array}$ & 100 & 17.0 \\
\hline $\begin{array}{l}\text { Nonhealth care } \\
\text { worker }\end{array}$ & $\begin{array}{l}\text { Personal support assistants } \\
\text { Hospital administration } \\
\text { Clerical } \\
\text { Support staff (eg, food services) } \\
\text { Research } \\
\text { Student } \\
\text { Other }\end{array}$ & 218 & 37.1 \\
\hline No response & No response & 3 & 0.5 \\
\hline Totals & & 588 & 100.0 \\
\hline
\end{tabular}


Table 2 Distribution of responses to primary questions by occupation type

\begin{tabular}{|c|c|c|c|c|c|c|c|c|c|}
\hline \multirow[t]{2}{*}{ Occupation } & \multicolumn{3}{|c|}{$\begin{array}{l}\text { Received the influenza } \\
\text { vaccination in 2003-2004 } \\
n(\%)\end{array}$} & \multicolumn{3}{|c|}{$\begin{array}{l}\text { Believes that the } \\
\text { vaccine is effective } \\
\mathbf{n}(\%)\end{array}$} & \multicolumn{3}{|c|}{$\begin{array}{l}\text { Believes that the vaccine } \\
\text { can cause influenza } \\
\text { n (\%) }\end{array}$} \\
\hline & Yes & No & $\overline{\text { Unsure }}$ & Yes & No & $\overline{\text { Unsure }}$ & Yes & No & Unsure \\
\hline Physician & $35(97.2)$ & I (2.8) & 0 & $33(89.2)$ & $\mathrm{I}(2.7)$ & $3(8.1)$ & 0 & $37(100)$ & 0 \\
\hline Nurse & $212(93.0)$ & $16(7.0)$ & 0 & $144(63.7)$ & $15(6.6)$ & $67(29.6)$ & $13(5.7)$ & $205(90.3)$ & $5(2.2)$ \\
\hline Other health care provider & 91 (92.9) & $7(7.1)$ & 0 & $64(63.0)$ & $3(3.0)$ & $34(34.0)$ & $3(3.0)$ & $92(92.9)$ & $3(3.0)$ \\
\hline Nonhealth care worker & $190(87.6)$ & $25(11.5)$ & $2(0.9)$ & $144(67.0)$ & $16(7.4)$ & $55(25.6)$ & $26(12.0)$ & $187(86.6)$ & $2(0.9)$ \\
\hline \multicolumn{10}{|l|}{ Total } \\
\hline Total (all professions) & $528(9 \mid .2)$ & $49(8.5)$ & $2(0.3)$ & $384(66.4)$ & $35(6.1)$ & $159(27.5)$ & $42(7.3)$ & $521(90.0)$ & $10(1.7)$ \\
\hline
\end{tabular}

influenza vaccine. Most common were doubts about the effectiveness of the formulation and fear of side effects, both reported in $24.2 \%$ of those who were nonimmunized. Table 4 summarizes the statistically significant univariate relationships between anticipated predictive factors and receipt of immunization. Table 5 shows adjusted odds ratios after logistic regression analysis. Not surprisingly, the majority of those who were immunized in 2003-2004 were much more likely to report that they would seek vaccination in the subsequent season $(P<0.001)$. However, being immunized in the previous season was not associated with being immunized currently $(P=1.000)$.

\section{Discussion}

Promoting influenza vaccination uptake among health care workers is important for a host of clinical, ethical, and economic reasons. The protection of patients, many of whom are at risk of serious complications of influenza, remains the most common argument. While there is some evidence that immunization of health care workers, in the absence of a campaign to immunize patients also, does not confer much of an advantage in curbing institutional infection rates, ${ }^{11}$ other studies have demonstrated that health care worker immunization is associated with reduced mortality

Table 3 Respondents' top stated reasons for not getting the influenza vaccination in 2003-2004

\begin{tabular}{lll}
\hline $\begin{array}{l}\text { Top reasons reported for not getting } \\
\text { the influenza vaccine in 2003-2004 }\end{array}$ & $\mathbf{n}$ & $\%$ \\
\hline Other & 17 & 27.4 \\
Belief that the vaccine does not work & 15 & 24.2 \\
Afraid of side effects & 15 & 24.2 \\
Never got around to it & 10 & 16.1 \\
Allergic & 8 & 12.9 \\
Belief that it weakens/harms the immune system & 7 & 11.3 \\
Pregnant or nursing & 5 & 8.1 \\
Belief that the vaccine can cause influenza & 4 & 6.5 \\
No contact with patients & 4 & 6.5 \\
\hline
\end{tabular}

in long-term care facilities, ${ }^{12,13}$ and with reduced health service usage and influenza-like illness among residents/ patients at the institution in question. ${ }^{14}$ Regardless, worker absenteeism due to seasonal influenza has been identified as a drain on already stretched clinical care budgets of many jurisdictions. ${ }^{15}$ The costs of absenteeism and of addressing an institutional outbreak essentially draw resources from other health needs. As a result, any attempt to increase health care workers' uptake of the seasonal influenza vaccine is readily defensible.

Previous attempts to identify barriers to uptake of the vaccine by professionals have consistently identified several factors, ie, fear of needles, ${ }^{7,16-18}$ inconvenience, ${ }^{1,16,19}$ fear of adverse events, ${ }^{1,17-21}$ and a belief that the vaccine is ineffective. ${ }^{1,7,17,19-21}$ Our data confirm these observations. Additionally, avoidance of medication ${ }^{7,17,20}$ and a belief in being in a "low-risk" population ${ }^{1,7,17,19,21}$ have been identified as contributing factors, but were not explored in the present study.

By logistic regression analysis, only one factor, ie, awareness of previous influenza immunization campaigns, was associated with receipt of influenza vaccine. This suggests that the commonly accepted barriers to vaccine uptake, ie, inconvenience and a fear of potential adverse events, can be influenced in a professional environment with a formal campaign focused on professional obligations and continuing employee education.

Table 4 Statistically significant univariate associations between predictive factors and receipt of vaccine in the 2003-2004 season

\begin{tabular}{ll}
\hline $\begin{array}{l}\text { Predictive factor (all positively } \\
\text { associated with vaccination) }\end{array}$ & $\begin{array}{l}\boldsymbol{P} \text { (Fisher's exact test } \\
\text { or two-sample } \boldsymbol{t} \text {-test) }\end{array}$ \\
\hline Increasing age & 0.006 ( $t$-test) \\
Increasing years working at CHEO & $<0.00$ I (t-test) \\
Had memory of the previous vaccination & $<0.00$ I (Fisher's exact test) \\
campaign & \\
The hours of the clinic were convenient & $<0.00$ I (Fisher's exact test) \\
\hline Abbreviation: CHEO, Children's Hospital of Eastern Ontario.
\end{tabular}


Table 5 Statistically significant associations between predictive factors and receipt of vaccine in the 2003-2004 season, after application of backwards elimination logistic regression

\begin{tabular}{ll}
\hline Predictive factor & Adjusted OR and 95\% CI \\
\hline $\begin{array}{l}\text { Belief that the vaccine can cause fever } \\
\text { Increasing age }\end{array}$ & $0.2(0-0.9)$ \\
Respondent occupation & $\mathrm{I} . \mathrm{I}(\mathrm{I} .0-\mathrm{I} . \mathrm{I})$ \\
- Nurse & $\mathrm{I} .2(0 . \mathrm{I}-10.4)$ \\
- Other health provider & $\mathrm{I} .7(0 . \mathrm{I}-22.2)$ \\
- Nonhealth care worker & $0.4(0 . \mathrm{I}-3.4)$ \\
- Physician (reference category) & $\mathrm{I} .0$ \\
$\begin{array}{l}\text { Knowledge of vaccination campaign } \\
\text { via letter with paycheck }\end{array}$ & $0.3(0.1-0.8)$ \\
Knowledge of previous vaccination & $4.0(\mathrm{I} .5-10.6)$ \\
campaign(s) & \\
\hline
\end{tabular}

Abbreviations: $\mathrm{Cl}$, confidence interval; OR, odds ratio.

The extent to which these results can be used to inform future vaccination campaigns depends, of course, upon the specific profile of the institution in question, ie, its history of vaccination campaigns, the degree to which employees have been exposed to influenza education, and the occupational mix of the staff. However, what is possibly universal is that reinforced knowledge of the existence of an influenza campaign is a (strong) predictor of immunization. Whether that reinforcement comes in the form of a formal reminder, as in the notes included with employees' paychecks, through efforts to make each campaign memorable, or through efforts to optimize and publicize the convenience of being immunized, reinforcing awareness of an influenza immunization campaign is an effective strategy for maximizing uptake.

Our data do not reflect the experiences of a population having undergone the media focus of the H1N1 outbreak. That season may have resulted in two competing trends, ie, an increased awareness of the need for, and availability of, influenza vaccination; and ironically perhaps a greater distrust of the health communications surrounding the need for vaccination, given the comparatively few numbers of serious H1N1 cases that arose in the US relative to some of the dire predictions that were made. Given that our data predate those experiences, any reflections on the impact of H1N1 on new attitudes toward flu immunization would be strictly speculative.

Given our low physician response rate, we cannot make any conclusions regarding very high immunization rates among this occupational group. Our overall low response rate might have been exacerbated by the decision to collect names and identification numbers, thus providing a disincentive for participation. The hospital's overall $23 \%$ nonvaccination rate compared with an $8.5 \%$ rate in our sample hints at something of a selection bias in our data, to the extent that those who were vaccinated were also more likely to have completed our survey. Therefore, any wisdom extracted from these data must be carefully considered. However, our results contrast with those of Kara et $\mathrm{a}^{22}$ who found that $33.7 \%$ of pediatric residents thought that the influenza vaccine was "unnecessary", with $69 \%$ of those who experienced minor adverse effects (such as arm soreness) expressing doubt that they would accept the vaccine in subsequent years due to those adverse events. Concern for adverse events, however minor, appears to be a consistently prominent factor in dissuading hospital workers from being immunized. This is disappointing, because it is hoped that health care workers would have an experienced and informed perspective that would convince them of the benefits of tolerating generally minor adverse events as the price for immunity.

More concerning still in the present study is the finding that more than a third of nurses who responded doubted the vaccine's effectiveness, while almost $8 \%$ believed that it can even cause influenza. This clearly speaks to a need for deeper and continuing professional education. Fortunately, none of the nonimmunized nurses cited a belief in the vaccine's ability to cause disease as a reason for their immunization status. Instead, nonimmunized nurses were more likely to be concerned about allergies, potential effects on pregnancies (or concerning a pregnancy), or adverse events.

The comparatively lower vaccination rates among nonhealth care workers, relative to that of clinicians, was not surprising, given the likelihood that that group had received less formal education about the benefits and risks of vaccination. Future studies are advised to explore some of the demographic factors affecting their decision to forego vaccination, such as religious beliefs, country of birth, and possibly more individualized personal experiences.

Our findings may not be generalizable to other health care facilities and are subject to several limitations. Our response rate was less than $30 \%$; respondents may not have been representative of all staff and physicians at CHEO; and since most respondents had in fact been immunized, the possibility of a degree of selection bias in our results persists. Moreover, the survey was not administered immediately after the 2003-2004 influenza immunization season and respondents may have been subject to recall bias. CHEO is a small, single-site pediatric facility which has historically had relatively high staff and physician influenza immunization rates. Despite the somewhat unique nature of CHEO, some wisdom can be garnered from these results for the purposes of designing immunization campaigns in other facilities, most 
notably the lesson that both the convenience of immunization and the regularity of reminders of a vaccination campaign can contribute to increased compliance rates.

Overall, the survey indicates a high degree of self-reported vaccine compliance, especially among those most likely to provide direct care to patients. The degree of misinformation reflected by respondents is relatively small, and is less evident amongst the more clinical groups. However, misconceptions about the nature and risks posed by the influenza vaccine are still prevalent among a small but noticeable fraction of clinical staff. This is concerning because these individuals are likely to be relied upon to communicate the nature of the vaccine to other stakeholders effectively and accurately, including patients and their families.

One seemingly contradictory finding was that knowledge about the vaccination campaign via a letter in the paycheck was predictive of not having been vaccinated, while memory of previous campaigns was predictive of having received the vaccination. This seems to reflect a tendency to dismiss paper notices, while emphasizing the importance of remembered experiences.

Despite our low response rate, the results herein suggest that awareness of a formal institutional influenza immunization campaign for staff and physicians was associated with receipt of influenza immunization, and therein lies the most novel aspect of our study. Indirectly, this would suggest that our current influenza vaccine campaign strategy is largely effective, though fails to elicit compliance among a minority of staff and physicians. However, given our population's overall immunization rates, the total effect of the campaign is nonetheless insufficient, especially when considering the vulnerable nature of the hospitalized patient population. Further appropriate strategies to increase vaccination uptake need to be explored, including expanded educational campaigns, reminders that are sent outside of just the peak season, and possibly even the consideration of mandatory vaccination requirements.

\section{Acknowledgment}

The authors would like to thank the staff and administration of CHEO for their cooperation in the undertaking of this study.

\section{Disclosure}

The authors report no conflict of interest in this work.

\section{References}

1. Eisenfeld L, Perl L, Burke G, et al. Lack of compliance with influenza immunization for the caretakers of neonatal intensive care unit patients. Am J Infect Control. 1994;22:307-311.
2. Jiménez-Jorge S, Savulescu C, Pozo F, et al; cycEVA Study Team, on behalf of the Spanish Influenza Sentinel Surveillance System. Effectiveness of the 2010-2011 seasonal trivalent influenza vaccine in Spain: cycEVA study. Vaccine. 2012;30:3595-3602.

3. Barret AS, Donnell JO, O'Hora A, et al. Effectiveness of 2010/2011seasonal influenza vaccine in Ireland. Ir Med J. 2012;105: $39-42$.

4. Potter J, Stott DJ, Roberts MA, et al. Influenza vaccination of health care workers in long-term-care hospitals reduces the mortality of elderly patients. J Infect Dis. 1997;175:1-6.

5. Lemaitre M, Meret T, Rothan-Tondeur M, et al. Effect of influenza vaccination of nursing home staff on mortality of residents: a clusterrandomized trial. JAm Geriatr Soc. 2009;57:1580-1586.

6. Elder AG, O'Donnell B, McCruden EA, Symington IS, Carman WF. Incidence and recall of influenza in a cohort of Glasgow healthcare workers during the 1993-1994 epidemic: results of serum testing and questionnaire. Br Med J. 1996;313:1241-1242.

7. Takayanagi IJ, Cardoso MR, Costa SF, Araya ME, Machado CM. Attitudes of health care workers to influenza vaccination: why are they not vaccinated? Am J Infect Control. 2007;35:56-61.

8. Seale $\mathrm{H}$, Macintyre CR. Seasonal influenza vaccination in Australian hospital health care workers: a review. Med J Aust. 2011;195: 336-338.

9. Anikeeva O, Braunack-Mayer A, Rogers W. Requiring influenza vaccination for health care workers. Am J Public Health. 2009;99: 24-28.

10. Wood NJ, Cashman PM. Influenza immunisation program at three tertiary paediatric hospitals in NSW in 2010. NS W Public Health Bull. 2011;22:230-232.

11. Thomas RE, Jefferson TO, Dermicheli V, Rivetti D. Influenza vaccination for health-care workers who work with elderly people in institutions: a systematic review. Lancet Infect Dis. 2006;6: 273-279.

12. Carman WF, Elder AG, Wallace LA, et al. Effects of influenza vaccination of health-care workers on mortality of elderly people in long-term care: a randomised controlled trial. Lancet. 2000;355:93-97.

13. Hayward A, Harling R, Wetten S, et al. Effectiveness of an influenza vaccine programme for care home staff to prevent death, morbidity, and health service use among residents: cluster randomised control trial. Br Med J. 2006;333:1241.

14. Oetgen WJ, Thomas WL. First, do no harm. Mandatory influenza vaccination for health care workers is a matter of patient safety. Trustee. 2011;64:39-40.

15. Grandi P, Franco G. Practising evidence-based occupational health in workers' groups: how to prevent sickness absence caused by influenza. Occup Med (Lond). 2005;55:7-9.

16. Al-Tawfiq JA, Antony A, Abed MS. Attitudes toward influenza vaccination of multi-nationality health-care workers in Saudi Arabia. Vaccine. 2009;27:5538-5541.

17. Sartor C, Tissot-Dupont H, Zandotti C, Martin F, Roques P, Drancourt M. Use of a mobile cart influenza program for vaccination of hospital employees. Infect Control Hosp Epidemiol. 2004;25:918-922.

18. Shah S, Caprio M. Availability of trivalent inactivated influenza vaccine to parents of neonatal intensive care patients and its effect on the healthcare worker vaccination rate. Infect Control Hosp Epidemiol. 2008;29:309-313.

19. Chittaro M, Turello D, Calligaris L, et al. Impact of vaccinating HCWs on the ward and possible influenza of avian influenza threat. Infection. 2009;37:29-32.

20. Habib S, Rishpon S, Rubin L. Influenza vaccination among healthcare workers. Isr Med Assoc J. 2000;2:899-901.

21. Simeonsson K, Summers-Bean C, Connolly A. Influenza vaccination of healthcare workers: institutional strategies for improving rates. N C Med J. 2004;65:323-328.

22. Kara A, Devrim I, Celik T, et al. Influenza vaccine adverse event and effect on acceptability in pediatric residents. Jpn J Infect Dis. 2007;60:387-388 


\section{Publish your work in this journal}

The International Journal of General Medicine is an international, peer-reviewed open-access journal that focuses on general and internal medicine, pathogenesis, epidemiology, diagnosis, monitoring and treatment protocols. The journal is characterized by the rapid reporting of reviews, original research and clinical studies across all disease areas.

A key focus is the elucidation of disease processes and management protocols resulting in improved outcomes for the patient.The manuscript management system is completely online and includes a very quick and fair peer-review system. Visit http://www.dovepress.com/ testimonials.php to read real quotes from published authors.

Submit your manuscript here: http://www.dovepress.com/international-journal-of-general-medicine-journal 